\title{
To compare the outcome of intramedullary nailing and locking compression plate fixation in treatment of proximal one third tibia fracture: A randomized control trial
}

\author{
Jain $\mathbf{S}^{1}$, Verma $\mathbf{R}^{2}$, Gaur $\mathbf{S}^{3}$, Gohiya $\mathbf{A}^{4}$ \\ ${ }^{1}$ Dr. Siddharth Jain, P.G. Resident, ${ }^{2}$ Dr. Rahul Verma, Associate Professor, ${ }^{3}$ Dr. Sanjeev Gaur, Professore, ${ }^{4}$ Dr. Ashish \\ Gohiya, Associate Professor. All are affiliated with Gandhi Medical College, Bhopal, MP, India.
}

Address for correspondence: Dr Siddharth Jain, Email: dr.sidrjain@gmail.com

\begin{abstract}
Background: Fractures of tibia shaft are most common of long bone fractures. Proximal tibia fractures account for approximately $5 \%$ to $11 \%$ of all tibial injuries and affect knee function and stability in most of the cases. Higher rates of malunion and increased incidence of associated complications have made these fractures particularly problematic. In recent years due to advancement in technique, proximal tibia plating and multidirectional locked intramedullary nailing, both have become widely used treatment modalities for proximal tibial metaphyseal fractures. This study was performed to compare plating and nailing options in proximal tibia extra-articular fractures. Materials and methods: This randomized prospective clinical study was conducted on 62 skeletally mature patients with closed extra-articular fracture of the proximal tibia treated with proximal tibial locking compression plating (PTLCP) or intramedullary nailing (IMN) by expert surgeons at a tertiary trauma center. Results: Postoperative hospital stay $(\mathrm{p}=0.043$ ), postoperative infection rate $(\mathrm{p}=0.036)$ were significantly high in the PTLCP group than in the IMN group, while rate of malunion $(\mathrm{p}=0.041)$ and nonunion(0.037) were significantly high in IMN group than in PTLCP group. However there was no clear advantage of either technique in terms of functional recovery of knee. Conclusion: Present comparison of IMN and PTLCP for the treatment of proximal one third tibia fracture showed no clear advantage of either technique. Present study concluded that both forms of treatment (IMN and PTLCP) provide adequate fracture stability.

Level of evidence: Level 2, randomized controlled trial.
\end{abstract}

Keywords: Intramedullary nailing (IMN), Proximal tibial locking compression plate (PLCTP), Proximal tibial extraarticular fractures, Prospective trial.

\section{Introduction}

Fractures of tibia shaft are most common of long bone fractures. Proximal tibia fractures account for approximately $5 \%$ to $11 \%$ of all tibial injuries and affect knee function and stability in most of the case [1]. Higher rates of malunion and increased incidence of associated complications have made these fractures particularly problematic [2]. Due to some recent design changes in intramedullary nails and advancement in adjunctive fixation techniques, popularity of IMN in treatment of this fracture has been increased [3-8]. Similarly, development of percutaneous application technique of proximal tibial LCP has allowed surgeons

\footnotetext{
Manuscript received: $23^{\text {rd }}$ Jan 2016

Reviewed: $02^{\text {nd }}$ Feb 2016

Author Corrected: $11^{\text {th }} \mathrm{Feb} 2016$

Accepted for Publication: $22^{\text {nd }}$ Feb 2016
}

to treat these complex fractures without the need for large surgical incision or threat of soft tissue stripping and subsequent failure due to infection or nonunion [916]. The optimal method of surgical treatment for fractures of proximal third tibial shaft remains debatable. The purpose of present study is to compare the outcome of these two treatment modalities and to assess the ability of each modality to obtain and maintain fracture reduction.

\section{Materials \& Methods}

The study was prospective randomized comparative study. Cases satisfying the inclusion criteria admitted in Hamidia Hospital during the study period of December 2011 to December 2013. Patients were followed up for 
a period of 6 months, evaluated radio logically and clinically with Tegner Lysholm knee scale [17] and the outcomes were used for comparison. For the purpose of present study, extraarticular proximal tibia was defined as a region extending from the knee joint distally 1.5 times the medial to lateral joint width. This correlated roughly to proximal $30 \%$ of the entire tibia [18]

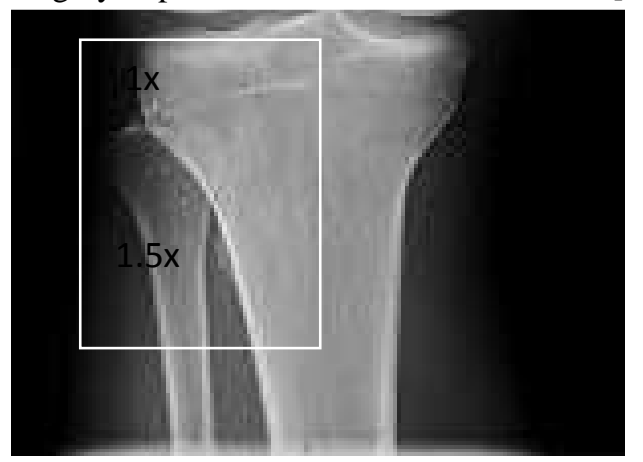

Figure 1: Area showing proximal tibia

Patients included in the study were skeletally matured (age group 18-80 years) having closed Proximal one third tibia extra-articular fracture, giving consent to participate in the study with at least 6 months follow up. Patients with intra-articular fracture, compound fracture, pathological fracture or refracture, fracture with vascular complications and contra lateral or ipsilateral lower extremity injury that would compromise function of knee, were excluded from the study. After approval by institutional ethics committee and informed consent, all patients were randomized into two treatment groups. Randomization was accomplished by random table number by computer. One group was treated by intramedullary nail while other group was treated by proximal tibial L.C.P.

80 patients with proximal tibia fracture reporting at Gandhi Medical College and Associated Hamidia Hospital, Bhopal between December 2011 \& December 2013 were treated with either intramedullary nail or proximal tibial LCP fixation. In 4 patients intra articular extension of fracture was found intra operatively, whereas 14 patients had follow up of less than 12 months, these were excluded from the study. Finally the present study comprised of 62 cases of proximal tibia fracture.

Detailed clinical history of patient was taken and clinical and radiological examination was done and specially evaluated for skin condition, any effusion and haemarthrosis. In acute injury, proper pain management and splintage was given. The fracture was classified according to AO classification [19]. The estimated blood loss, average operation time, intraoperative complications were recorded.

All surgical procedures were performed by the skilled senior surgeons. All fixations were done under tourniquet. The patient was positioned supine on the operation table. Temporary anatomical reduction was achieved by closed manipulation before nailing. An incision by splitting patellar tendon extending from lower pole of patella to tibial tuberocity was used to open the joint. The high nail entry point was taken in line with the shaft of tibia. Antero-posterior or mediolateral blocking screws were also used only in few cases. In all the cases proximal tibia nail was used.. The surgical wound closure was done in layers.

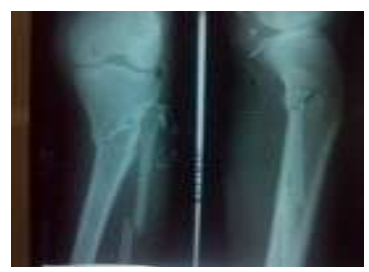

A
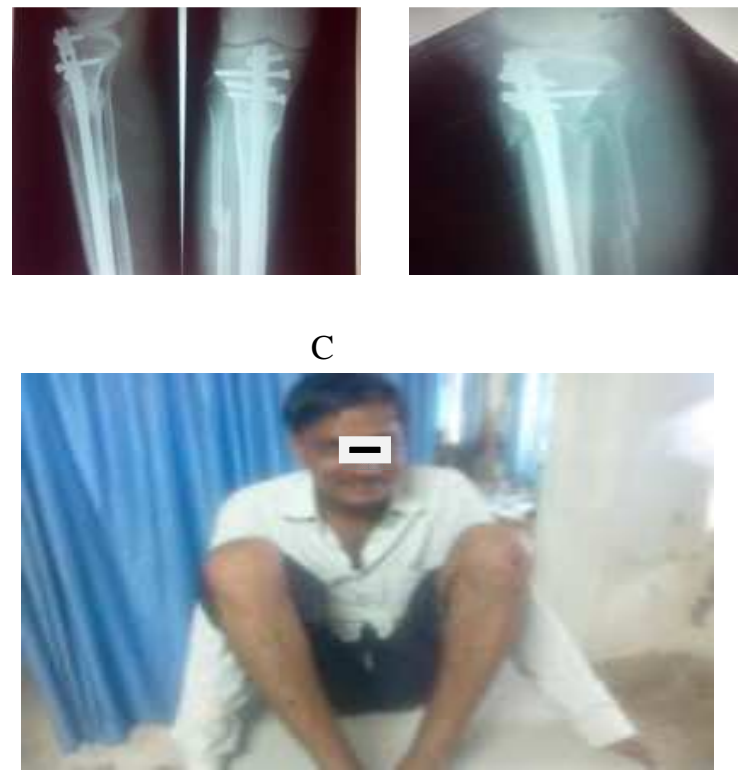

D

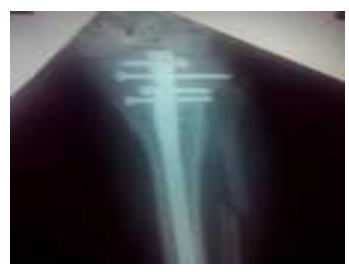

B
Figure 2: After injury (A), immediate postop (B), After I year followup (C, D)

With similar preparation all PTLCP reduction and length were achieved by linear manual traction or by application of femoral distracters. In some cases open reduction and internal fixation with PTLCP was done while in few of cases were performed by minimally invasive technique Reduction re-evaluated, under image 
intensifier. When satisfactory reduction was achieved, plate was fixed with appropriate size screws. Muscle, fascia and skin closed in layers over a drain.
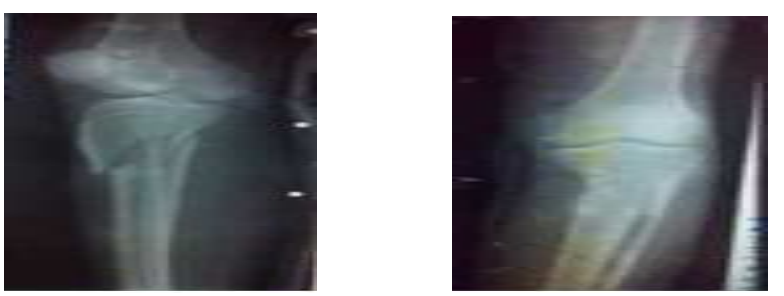

A

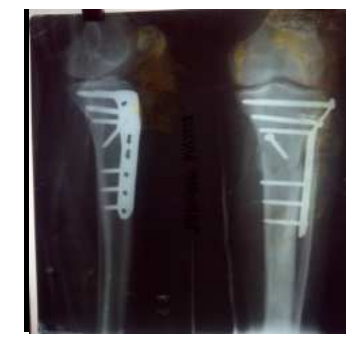

B

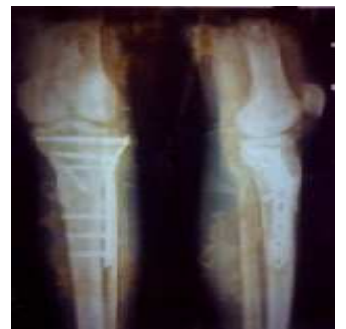

$\mathrm{C}$

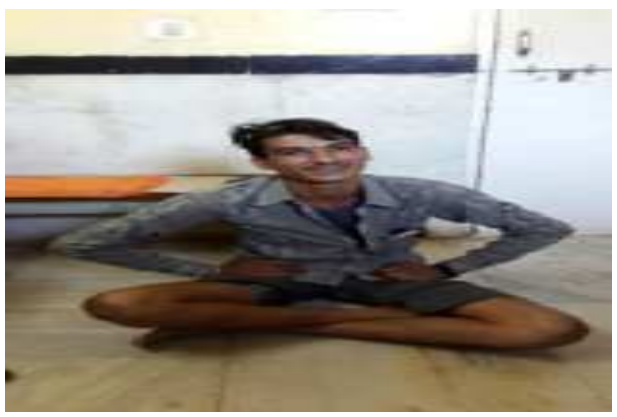

D

Figure 3: After injury (A), immediate postop (B), After I year follow up $(\mathrm{C}, \mathrm{D})$

Standard protocol for postoperative antibiotic, check dressing, physiotherapy and suture removal was followed.. Follow up visits were planned at 2 weeks, then monthly up to 12 months. At every follow up, patients were assessed clinically for pain, swelling, knee range of motion, quadriceps strength, functionally by Tegner Lysholm Score [17]. Radiological assessment was done pre-operatively, immediate postoperative, and at every follow-up. All the patients had similar physiotherapy protocol with full normal activity allowed after the quadriceps power became $80 \%$ of the contralateral side and radiological union became appreciable. All the patients followed similar protocol for weight bearing and mobilization.

\section{Radiological evaluations used for study purpose were-}

Union- Bridging cortical bone on at least two cortices combined with ability to bear full weight [16].

Nonunion - Failure of progressive radiological healing over a four month period [12].

Malunion - Any angular malreduction $>5^{0}$ or greater in any plane [16]

Both the immediate postoperative and final follow up radiographs were compared for the accuracy of the reduction and final alignment measurement were performed for frontal (valgus and varus) and sagittal plane (flexion and extension) deformities. The measurement technique was according to Freedman and Johnson [20]. The frontal plane normal value was considered 0 degree whereas 8 degree was subtracted from sagittal measurement to allow for the posterior tilt of tibia. The averages were recorded and comparisons were then made within and between the IMN and PTLCP groups.

All data were entered into a pro forma. The statistical analysis was performed by an independent statistician using the Statistical Package for the Social Sciences (SPSS version 22.0; SPSS, Chicago, IL, USA). The chosen level of significance was $\mathrm{p}<0.05$. The two groups were compared with respect to age, sex, operating time, hospital stay, infection rate, fracture union time, angulation of the fracture, and the knee range of motion. The parameters were compared between the groups. A paired-sample t test was used for the interval data (age, operating time, length of hospital stay, fracture union time, postoperative angulation, and functions of the knee).

\section{Results}

Age incidence ranged from 19 to 72 years with. The combined average age was 38.61 years. Over all M: F ratio in the study was 9.33. Young male are more involved in outside, productive, high energy activities so male more commonly suffer from this fracture. In both the group, both limbs were almost equally affected. In both the groups, RTA fallowed by fall from height was the two most common modes of trauma. Majority of fractures were of type A33 (41.93\%, 13/31), significant communition was present in these types of fractures. Most of the cases in both the groups were operated within ten days of injury. 
In most of the cases $96.77 \%$ (60/62) operative time is < 2 hours. One case in each group required more than 2 hour. According to this data, PTLCP fixation takes more time than intramedullary fixation. There was no heavy blood loss in any of the case, because all the fixations are done under tourniquet. Less blood loss occurred during intramedullary nailing as compared to locking plate fixation. All other observations have been described in following table.

\section{Table 1: Data Description}

\begin{tabular}{|c|c|c|c|}
\hline Parameters & Group 1 & Group 2 & $P$ value \\
\hline Age(Average) & 36.02 years & 40.8 years & 0.834 \\
\hline \multicolumn{4}{|l|}{ Sex } \\
\hline Male & 30 & 26 & 0.964 \\
\hline Female & 2 & 4 & \\
\hline \multicolumn{4}{|l|}{ Side of limb affection- } \\
\hline Right & $44 \%$ & $53 \%$ & 0.867 \\
\hline Left & $56 \%$ & $47 \%$ & \\
\hline \multicolumn{4}{|l|}{ Mode of trauma } \\
\hline Road traffic accident & 24 & 26 & 0.307 \\
\hline Fall from hight & 6 & 4 & \\
\hline Assault & 2 & 0 & \\
\hline Other & 0 & 0 & \\
\hline \multicolumn{4}{|l|}{ Fracture type - extraarticular } \\
\hline $\begin{array}{l}41 \mathrm{~A} 2 \\
41 \mathrm{~A} 3\end{array}$ & $\begin{array}{l}8 \\
24\end{array}$ & $\begin{array}{l}6 \\
24\end{array}$ & 0.563 \\
\hline $\begin{array}{l}\text { Injury operation interval } \\
\text { (in days) }\end{array}$ & 7.4 days & 7.06 days & 0.805 \\
\hline $\begin{array}{l}\text { Average operative time } \\
\text { (in minnuts) }\end{array}$ & 61.25 & 72.8 & 0.084 \\
\hline Open reduction & None & $47 \%$ & \\
\hline Blood loss (average) & $50-100 \mathrm{ml}$ & $100-150 \mathrm{ml}$ & \\
\hline Infection & 2 & 5 & 0.036 \\
\hline Non union & 4 & 2 & 0.037 \\
\hline $\begin{array}{l}\text { Disribution of malunion } \\
\text { anterior angulation }\end{array}$ & 4 & 2 & 0.041 \\
\hline Posterior angulation & 0 & & \\
\hline Valgus malunion & 0 & 0 & \\
\hline Varus malunion & 2 & 0 & \\
\hline Duration of hospital stay (Days) & 11.3 & 19.1 & 0.043 \\
\hline Union time (Weeks) & 16.2 & 18.1 & 0.762 \\
\hline $\begin{array}{l}\text { Tegner lyshlom's knee score } \\
\text { (Average) }\end{array}$ & 85 & 84 & 0.857 \\
\hline
\end{tabular}

\section{Discussion}

Proximal tibia extraarticular fractures often occur in people belonging to young active age group. In present study, the overall mean age was 38.61 years (range 19 to 72 years). Schultz M. et al [14] has shown mean age of 42 years in their study. While Cole, et al [9] have shown mean age of 45 years in their study. $90.3 \%$ of the patients in present study were male and only $9.7 \%$ were females. Thus results of present study were well similar with results of previous studies $[9,14,18]$. 
In present study, road traffic accident was found to be the major cause of this fracture. In $80.6 \%$ of the cases, mode of trauma was road traffic accident and in $16 \%$ of the cases, mode of trauma was fall from height while $3.2 \%$ of the cases had history of assault by hard and blunt object. Various previous studies have also shown similar distribution of mode of injury [9,18] . Lindval E. et al [18] and Vidhyadhar S. et al [22] have also shown high prevalence of 41A3 in their study. Most common type of fracture observed in present study was 41A3. 77.41\%. (48/62) patients in study had 41A3 type of fracture while rest $22.59 \%$ (14/62) patients had 41A2 type of fracture. 41A3 fractures represent significant communition which requires a large amount force to occur.

In present study the average injury operation delay was 7.23 days. In study of Cole et al [9] and Fanliu et al [24] average injury operation interval was around 7 days. While Singh V.K. et a [24] Shown only 29 hour, as average injury operation delay. Poor soft tissue condition, associated medical illnesses, associated injuries, feasibility of implant and many other factors were responsible for this delay in fixation in present study. There is no significant data available in literatures about the duration of surgery for both the treatment modality. In present study, most of the fixations were done within 2 hours. Proximal one third extraarticular fracture often fixed under tourniquet so no significant blood loss occurred intraoperatively. Probably because of this reason, most of the similar studies had not taken this parameter for evaluation Malunion of $>5^{0}$ in proximal tibial fractures, after fixation is well documented $[7,18]$.

Table 2: Malunion rate in studies with imn

\begin{tabular}{|l|l|l|l|}
\hline Study & $\begin{array}{l}\text { Extra-articular proximal } \\
\text { tibia fractures }\end{array}$ & $\begin{array}{l}\text { Malunion } \\
\left(>\mathbf{5}^{\mathbf{0}} \text { degree }\right)\end{array}$ & No. of cases malunion \\
\hline Lange et al.[25] & 32 & 23 & $\begin{array}{l}16 \text {-apex ant. } \\
13 \text { valgus (6 with both plane) }\end{array}$ \\
\hline Tornetta et al.[26] & 30 & 7 & $\begin{array}{l}4 \text { apex ant. } \\
3 \text { coronal }\end{array}$ \\
\hline Nork et al.[16] & $30-33$ & 3 & 1 varus \\
\hline Lindvall et al.[18] & 22 & 9 & $\begin{array}{l}8 \text { apex anterior } \\
2 \text { valgus (I with both plane) }\end{array}$ \\
\hline Present study & 16 & 3 & $\begin{array}{l}2 \text { apex anterior } \\
1 \text { varus }\end{array}$ \\
\hline
\end{tabular}

Table 3: Mal union rate in studies with PTLCP

\begin{tabular}{|l|l|l|l|}
\hline Study & $\begin{array}{l}\text { Extraarticular } \\
\text { proximal tibia fracture }\end{array}$ & Malunion $\mathbf{> 5}$ & No. of cases malunion \\
\hline Cole et al.[9] & 28 & 08 & $\begin{array}{l}\text { I valgus } \\
6 \text { apex ant I apex posterior }\end{array}$ \\
\hline Ricci et al.[13] & 18 & 5 & 2 valgus 2 apex ant., 1 apex post \\
\hline Lindvall et al.[18] & 34 & 7 & $\begin{array}{l}5 \text { apex anterior with 1 varus, 2 apex } \\
\text { post. }\end{array}$ \\
\hline Vidhyadhar S. et al.[22] & 45 & 7 & $\begin{array}{l}4 \text { apex anterior, } \\
\text { 3 valgus }\end{array}$ \\
\hline Present study & 15 & 2 & $\begin{array}{l}1 \text { apex anterior } \\
\text { I varus }\end{array}$ \\
\hline
\end{tabular}

In present the pooled rate of malunion was greater after intra-medullary nailing $(6 / 32 ; 18.75 \%)$ than after plating $(4 / 30$, 13.2\%). There are some anatomical peculiarities of the proximal one third tibia that are responsible for the axial deviations with intra medullary nailing. The proximal tibia is triangular. The antero-posterior width of the tibia is narrower on the medial side this encourage the malalignment in coronal plane. Anterior curvature mal-alignment is encouraged by a tibial plateau that is directed posteriorly between $3^{\circ}$ and $7^{\circ}$ and also by the pull of the patellar ligament inserted on to the tibial tuberosity [18]. Secondary mal-alignment which is common after plating is also promoted by a dorsally displaced axis of loading. Medial tilting of the proximal fragment is created by a medially located axis of loading. To avoid this complication in nailing of proximal one third tibia shaft fracture, some specific additional 
techniques can be used. These include, adjusting the proximal starting point [7], nailing in semiextended position [5], using an adjuvant plate $[8,28]$ and placing blocking screw [6] before nailing. Both Ricci et al [13] and Krettak et al [28] supported the clinical effectiveness of blocking screw. In Present study, in 18.75\% (6/32) patients of Group I, blocking screw was used. Only mediolateral blocking screws were used in these patients while antero- posterior blocking screws were not used in any of the cases. Number of cases of IMN fixation in which blocking screw is used form a very small pool so its effectiveness cannot be proved statistically by present study. Other additional techniques include use of transfixation pin distracter [28], percutaneous clamps [17], temporary pinning for fracture manipulation [17] and use of a nail with a more proximally placed Herzog curve [29]. In present study proximal tibial nail which has a more proximally placed Herzog curve, was used. To avoid these complications in PTLCP fixation Oh C.W. et al [31] advised double plating in highly unstable fracture. Bolhofner et al [32] suggested use of composite fixation (lateral plate with medial external fixator) in patient with extraarticular proximal tibia fracture with varying degree of open and closed soft tissue injury. In present study only interfragmentary screws were used as additional technique in $4 / 30$ patients of Group II.

Many of the previously published reports on PTLCP have documented similar malunion rates to recent studies on IMN as a treatment modality of proximal one third extraarticular tibia fractures. But in present study rate of mal union was higher in Group I treated with IMN as compared to the Group II treated with PTLCP. 18.75\% (6/32) cases develop malunion in Group I while only 13.2\% (4/30) in Group II develop malunion in followup. In treatment of proximal one third extra articular tibia fracture similar results of high rate of malunion $36 \%(16 / 22)$ in cases treated by IMN as compare to $15 \%$ (5/34) in cases treated by PTLCP shown by comparative study of Lindvall et al.[18] This study reported that malunion is more prevalent in the sagittal plane than the coronal plane for both implants. Their findings are consistent with the present study findings. High union rates for both the modalities of fixation (IMN \& PTLCP) were reported by various studies $[7,8,10,11-15,22,26,28]$

Table 4: Comparison of nonunion rate in various studies

\begin{tabular}{|l|l|l|}
\hline \multirow{2}{*}{ Study } & Rate of Non-Union \\
\cline { 2 - 3 } & IMN & Plate \\
\hline Bhandari et al.[33] & $3.51 \%(7 / 199)$ & $1.35 \%(1 / 74)$ \\
\hline Lindvall et al.[18] & $23 \%(5 / 22)$ & $6 \%(2 / 34)$ \\
\hline Present study & $12.5 \%(4 / 32)$ & $6.6 \%(2 / 30)$ \\
\hline
\end{tabular}

In present study union rates for IMN of proximal tibial fractures was $87.5 \% \%$ and $93.4 \%$ reported for PTLCP. High union rates were consistent with previously published reports. Distraction, lack of cortical contact, soft tissue interposition, poor vascular supply, persistent high grade infection or excessive mal alignment at the fracture site may be the causative factors for nonunion after fixation in patients treated with IMN, while soft tissue interposition, persistent deep high grade infection seems to be responsible for nonunion in patients treated with PTLCP. Overall pooled rate of nonunion was low, with significant difference between intramedullary nailing (4/32) $12.5 \%$ and plating (2/30) 6.6. Over all mean union time was 17.15 weeks. Mean union time in Group 1 was 16.2 weeks (range 14-24 weeks) while mean union time in Group II is 18.1 weeks (range 16-22 weeks). Similar results were shown by various other studies $[22,23,28,34]$. In various studies, infection rates range from $0-8 \%$ for IMN and 0-6 \% for PLP. Present study found the overall infection rate $11.29 \%$ (7/62). $6.25 \%$ (2/32) cases in Group I developed infection in post operative period while in $16.6 \%(5 / 30)$ of the cases developed infection. In one case, of Group II implant removal was done due to persistence of infection and nonunion. In present study, the pooled rate of infections after intramedullary nailing was $6.25 \%(2 / 32)$ while after plating was (5/30) 16.6\%. In other studies, following results were reported for infections

Table 5: Comparison of infection rate in various studies

\begin{tabular}{|l|l|l|}
\hline Study & IMN Group & PTLCP Group \\
\hline Bhandari et al. [33] & $2.5 \%$ & $14 \%$ \\
\hline Lindvallet al. [18] & $28 \%$ & $24 \%$ \\
\hline Oh C W. et al. [31] & - & $0 \%$ \\
\hline Present study & $6.25 \%$ & $16.6 \%$ \\
\hline
\end{tabular}


Over all higher rate of infection in PTLCP group may be attributable to large incision, soft tissue damage, shortcomings in addressing these soft tissue injuries, additional co morbidities, or a lower threshold to return to the operating room for irrigation and debridement. In the view of various surgeons when proximal fragment of the fracture was short, it was found difficult to achieve and maintain reduction particularly with IMN. Various techniques like blocking screw placement, temporary pinning had to be used when these kinds of fractures were dealt with IMN for satisfactory fracture reduction. However in plating technique, placement of multiple cancellous screws in various directions in the proximal fragment helped in maintaining this short fragment in reduced position. Contrary to this scenario when the proximal fragment was longer, a longer plate had to be inserted to address the fracture as a consequence of which the patients developed symptoms like pain and irritation due to impingment of soft tissue by hardware as well as in some previous studies patient reported with breakage of plate and loosening of screws which can be attributed to the plate, being a load bearing device rather than a load sharing one. Similar complaints were encountered less often with nailing system as was supported by a study on primary stability of various forms of osteosynthesis in the treatment of fractures of the proximal tibia by Lindvall E. et al [18]. In various studies of extra articular proximal tibia fractures treated with IMN, full weight bearing has ranged from 8-16 weeks depending upon the fracture location, fracture pattern and surgeon preference [18, 16]. Studies often state "weight bearing advanced as tolerated" but this does not accurately define when full weight bearing actually occurred and therefore can't be used to determine if either technique allow for earlier full weight bearing without implant failures. Unfortunately present study could not document the benefit of either of the treatment modality in this parameter.

Most of the patients $61.2 \%$ (19/31) of both the groups show good result on evaluating patient clinically and functionally with Tegner Lysholm knee scale [17]. In Group I, 62.5\% (20/32) and 60\%, (18/30) in Group II gave good results in follow-up. $12.5 \%$ patient of Group I show excellent results whereas 13.3\% (4/30) in Group II show excellent results. $12.5 \%$ of the patients in Group I show fair results as compared to $19.8 \%$ (6/30) cases which showed fair results in Group II. While $12.5 \%$ of the cases in Group I showed poor result as compare to $6.6 \%$ of cases with poor results in Group II. As per present knowledge none of the similar comparative study used Lysohlm score to evaluate functional and clinical outcome of the patient. In a study on intra medullary fixation of proximal tibia fracture by Vidhyadhar S. et al.[22], Lower Extremity Functional Score was used and average score of 96 (range 89-100\% SD=3.4\%) was found which show excellent results in most of the cases. Singh V.K. et al.[24] in their study used Klemm and Borner scoring system and shown excellent results in $73 \%$ of the patients. While Kim J.W. et al [34] used knee society score and found excellent results after fixation, in $76.7 \%$ of the patients with proximal tibia fracture. It seems that present study have shown results inferior to these studies, however it is difficult to compare the results as in different studies different scores were used. Average score in group I was 85 while in group II was 84 and the difference was insignificant statistically. Functional recovery of knee was found to be comparable with both the implant. The present study had certain limitations such as: Short sample size and multiple surgeons.

\section{Conclusions}

This prospective randomized comparative study concludes that in treatment of proximal tibia extra articular fracture use of PTLCP and IMN gives comparable results. Use of PTLCP is associated with more intra operative blood loss, higher postoperative infection rate and longer duration of hospital stay whereas use of IMN associated with higher rates of malunion and nonunion. However there is no difference in functional outcome between IMN and PTLCP. To validate this issue further a large sample size multicentric randomized controlled study is recommended. Overall proximal one third extraarticular tibia fracture is complicated and problematic fracture to deal with and is commonly associated with significant soft tissue damage. High grade of surgical skills are required to deal these fractures as fixation of proximal one third extraarticular tibia fracture is technically demanding surgery regardless of the implant.

\section{Funding: Nil \\ Conflict of interest: None. \\ Permission of IRB: Yes}

\section{Bibliography}

1. Court-Brown CM, McBirnie J. The epidemiology of tibial fractures. J Bone Jt Surg Br. 1995;77(3):417-21.

2. DeCoster TA, Nepola JV, el-Khoury GY. Cast brace 
treatment of proximal tibia fractures. A 10-year followup study. Clin Orthop Relat Res. 1988;231:196-04.

3. Peindl RD, Zura RD, Vincent A et al. Unstable proximal extraarticular tibia fractures: a biomechanical evaluation of four methods of fixation. J Orthop Trauma. 2004 Sep;18(8):540-5.

4. Laflamme GY, Heimlich D, Stephen D, Kreder HJ, Whyne CM Proximal tibial fracture stability with intramedullary nail fixation using oblique interlocking screws. J Orthop Trauma. 2003 Aug;17(7):496-02.

5. Tornetta P, Collons E. Semiextended position of intramedullary nailing of the proximal tibia. Clin Orthop Relat Res. 1996;328:185-9. doi: 10.1097/00003086-199607000-00029

6. Krettek C, Stephan C, Schandelmaier P, et al. The use of Poller screws as blocking screws in stabilizing tibial fractures treated with small diameter intramedullary nails. J Bone Jt Surg Br. 1999;81:96368. doi: 10.1302/0301-620X.81B6.10000.

7. Beuhler KC, Green J, Woll TS, Duwelius PJ. A technique for intramedullary nailing of proximal third tibia fractures. J Orthop Trauma. 1997;11(3):218-23. doi: 10.1097/00005131-199704000-00014

8. Matthews DE,McGuire R, Freeland AE. Anterior unicortical buttress platting in conjunction with an undreamed intramedullary nail for treatment of very proximal tibial diaphyseal fractures. Orthopedics. 1997 Jul;20(7):647-8

9. Cole PA, Zlowodzki M, Kregor PJ. Treatment of proximal tibia fractures using the less invasive stabilization system: surgical experience and early clinical results in 77 fractures. J Orthop Trauma.2004;18(8):528-35. doi: 10.1097/00005131200409000-00008.

10. Stannard JP, Wilson TC, Volgas DA, Alonso JE, Minimally Invasive Percutaneous Plate Osteosynthesis Of Proximal Tibial Fractures Using Locking Compression Plate - A Prospective Study ,Injury, 2003 Aug; Vol. 34 Suppl 1, pp. A36-42

11. Ricci W.M., O'Boyle M, Borrelli J, Bellabarba C, Sanders R. Fractures of the proximal third of the tibial shaft treated with intramedullary nails and blocking screws. J Orthop Trauma. 2001 May;15(4):264-70

12. Egol KA, Tejwani NC, Capla EL, Wolinsky PL, Koval KJ. Staged management of high-energy proximal tibia fractures (OTA types 41): the results of a prospective, standardized protocol. J Orthop Trauma. 2005 Aug;19(7):448-5

13. Ricci WM, Rudzki JR, Borrelli J Jr. Treatment of complex proximal tibial fractures with LISS, J Orthop Trauma. 2004 Sep;18(8):521-7

14. Schutz M, Kaab MJ, Haas N. Stabilization of proximal tibia fractures with the LIS-System: early clinical experience in Berlin. Injury. 2003;34(Suppl 1):A30-A35. doi: 10.1016/S0020-1383(03)00255-9

15. Boldin C, Finkahauser F, Hofer HP, et al. Three year results of proximal tibia fracture treated with LISS. Clin Orthop Relat Res. 2006 Apr;445:222-9.

16. Nork SE, Barei DP, Schildhauer TA, Agel J, Holt SK, Schrick JL, et al. Intramedullary nailing of proximal quarter tibial fractures. J Orthop Trauma. 2006;20(8):523-28. doi: 10.1097/01.bot.0000244993.60374.d6.

17. Tegner Y, Lysholm J. Rating systems in the evaluation of knee ligament injuries. Clin Orthop Relat Res. 1985 Sep;(198):43-9.

18. Lindvall E, Sanders R, Dipasquale T, Herscovici D, Haidukewych G, Sagi C. Intramedullary nailing versus percutaneous locked plating of extra-articular proximal tibial fractures: comparison of 56 cases. J Orthop Trauma. 2009;23:485-92. doi: 10.1097/BOT.0b013e3181b013d2.

19. Müller, M.E., Nazarian, S., Koch, P. et al, The comprehensive classification of fractures of long bones. in: 1st ed. Berlin. Springer-Verlag, Heidelberg, New York; 1990. [Crossref]

20.Freedman EL, Johnson EE. Radiographic analysis of tibial fracture malalignment following intramedullary nailing. Clin Orthop Relat Res.1995 Jun;(315):25-33

21. Koval K, Clapper M, Brumback R, et al. Complications of reamed intramedullary nailing of the tibia. J Orthop Trauma. 1991;5(2):184-9. doi: 10.1097/00005131-199105020-00011. 
22. Vidyadhara S. Sharath K. Rao. Prospective study of the clinico-radiological outcome of interlocked nailing in proximal third tibial shaft fracture. Int. J. Care Injured (2006)37; 536-42

23. Fan Liu, Ran Tao, Yi Cao, Youhua Wang, Zhenyu Zhou, Hong Wang,YongqiangGu. The role of LISS (less invasive stabilisation system) in the treatment of peri-knee fractures. Province, PR China.Injury. 07/2009; 40(11):1187-4

24. Singh V.K.,1 Y Singh,2 PK Singh,3 RK Goyal,2 H Chandra2 Unreamed intramedullary nailing with oblique proximal and biplanar distal interlocking screws for proximal third tibial fractures Journal of Orthopaedic Surgery 2009;17(1):23-7

25. Lang GJ, Cohen BE, Bosse MJ, Kellam JF. Proximal third tibial shaft fractures. Should they be nailed? ClinOrthopRelat Res. 1995 June;(315):64-74

26. Tornetta P, Collons E. Semiextended position of intramedullary nailing of the proximal tibia. Clin Orthop Relat Res. 1996;328:185-9. doi: 10.1097/00003086-199607000-00029.

27. Dunbar RP, Nork SE, Barei DP, Mills WJ. Provisional plating of Type III open tibia fractures prior to intramedullary nailing. J Orthop Trauma. 2005 Jul;19(6):412

28. Krettek C, Stephan C, Schandelmaier P, et al. The use of Poller screws as blocking screws in stabilizing tibial fractures treated with small diameter intramedullary nails. J Bone Jt Surg Br. 1999;81:963-8. doi: 10.1302/0301-620X.81B6.10000.

29. Moed BR, Watson JT. Intramedullary nailing of the tibia without a fracture table: the transfixation pin distractor technique. J Orthop Trauma. 1994;8(3):195202. doi: 10.1097/00005131-199406000-00003

30. Henley MB, Meier M, Tencer AF. Influences of some design parameters on the biomechanics of the unreamed tibial intramedullary nail. J Orthop Trauma. 1993;7(4):311-9. doi: 10.1097/00005131-19930800000003.

31. Oh CW, Oh JK, Kyung HS, Jeon IH, Park BC, Min WK, Kim Pt. Minimally Invasive Percutaneous Plate Osteosynthesis Of Proximal Tibial Fractures Using Locking Compression Plate - A Prospective Study. ActaOrthopaedica [ActaOrthop], ISSN: 1745-3674, 2006 Jun; Vol. 77 (3), pp. 524-30;

32. Bolhofner BR. Indirect reduction and composite fixation of extraarticular proximal tibial fractures. Clin Orthop Relat Res. 1995 Jun;(315):75-83

33. Bhandari M, Audige L, Ellis T. Operative treatment of extraarticular proximal tibial fractures. J Orthop Trauma. 2003;17(8):591-5. doi: 10.1097/00005131200309000-00013.

34. Kim J. W., Chang-Wug Oh, corresponding author Won-Ju Jung, MD, and Ji-Soo Kim, MD Minimally Invasive Plate Osteosynthesis for Open Fractures of the Proximal Tibia ClinOrthop Surg. 2012 December; 4(4): 313-20.

\section{How to cite this article?}

Jain S, Verma R, Gaur S, Gohiya A To compare the outcome of intramedullary nailing and locking compression plate fixation in treatment of proximal one third tibia fracture: A randomized control trial . Int J Med Res Rev 2016;4(2):245253. doi: 10.17511/ijmrr.2016.i02.020. 